\title{
Práticas de cuidado em um CAPS-AD: Sobre a abstinência e redução de danos
}

\author{
Care practices in a CAPS-AD: Abstinence and harm reduction \\ Prácticas de cuidado en un CAPS-AD: Abstinencia y reducción de daños
}

Recebido: 08/05/2021 | Revisado: 16/05/2021 | Aceito: 17/05/2021 | Publicado: 04/06/2021

\author{
Diogo Henrique Tavares \\ ORCID: https://orcid.org/0000-0002-0961-6421 \\ Universidade Federal de Pelotas, Brasil \\ E-mail: enf.diogotavares@gmail.com \\ Aline Basso da Silva \\ ORCID: https://orcid.org/0000-0001-6711-4553 \\ Universidade Federal de Pelotas, Brasil \\ E-mail: alinee_basso@hotmail.com \\ Fabiane Machado Pavani \\ ORCID: https://orcid.org/0000-0002-3858-8036 \\ Universidade Federal do Rio Grande do Sul, Brasil \\ E-mail: fabianepavani04@gmail.com \\ Cristiane Kenes Nunes \\ ORCID: https://orcid.org/0000-0002-8355-568X \\ Prefeitura de Canoas, Brasil \\ E-mail: cris_kenes@ hotmail.com \\ Beatriz Franchini \\ ORCID: https://orcid.org/0000-0003-3122-7091 \\ Universidade Federal de Pelotas, Brasil \\ E-mail: beatrizfranchini@hotmail.com \\ Cândida Garcia Sinott Silveira Rodrigues \\ ORCID: https://orcid.org/0000-0001-7719-0621 \\ Universidade Católica de Pelotas, Brasil \\ E-mail: candidasinott@hotmail.com
}

\begin{abstract}
Resumo
Objetivo: analisar as práticas de cuidado ao usuário de drogas em um CAPS ad sobre a perspectiva da abstinência e redução de danos. Método: pesquisa qualitativa, desenvolvida em um serviço de saúde no interior localizado na fronteira entre Rio Grande do Sul/ Brasil e Uruguai. Os dados foram coletados com seis profissionais entre abril e setembro de 2017 por meio de entrevista semiestruturada como fonte de coleta de dados e análise de conteúdo para a sistematização dos achados. Resultados: A partir da análise, as informações foram organizadas em quatro categorias temáticas: Os testes toxicológicos e as finalidades de sua utilização; Acolhimento e os testes rápidos para IST's e toxicológicos; A abstinência comprovada como critério de encaminhamento para a UAT; e As Consequências perante a imposição da abstinência no processo de reabilitação. Conclusão: É necessário refletir o processo de cuidado que inclua ações de redução de danos, excluindo o foco do tratamento na abstinência.
\end{abstract}

Palavras-chave: Serviços comunitários de saúde mental; Saúde mental; Transtornos relacionados ao uso de substâncias; Usuários de drogas; Redução do dano.

\begin{abstract}
Objective: to analyze the care practices for drug users in a CAPS ad on the perspective of abstinence and harm reduction. Method: qualitative research, developed in a health service in the countryside located on the border between Rio Grande do Sul / Brazil and Uruguay. Data were collected from six professionals between April and September 2017 through semi-structured interviews as a source of data collection and content analysis for the systematization of the findings. Results: From the analysis, the information was organized into four thematic categories: Toxicological tests and the purposes of their use; Reception and rapid tests for STIs and toxicological tests; Proven abstinence as a criterion for referral to the UAT; and The Consequences of imposing abstinence in the rehabilitation process. Conclusion: It is necessary to reflect on the care process that includes harm reduction actions, excluding the focus of treatment on abstinence.
\end{abstract}

Keywords: Community mental health services; Mental health; Disorders related to substance use; Drug users; Harm reduction.

\section{Resumen}

Objetivo: analizar las prácticas de atención a los usuarios de drogas en un CAPS ad sobre la perspectiva de la abstinencia y la reducción de daños. Método: investigación cualitativa, desarrollada en un servicio de salud en el 
campo ubicado en la frontera entre Rio Grande do Sul / Brasil y Uruguay. Se recolectaron datos de seis profesionales entre abril y septiembre de 2017 a través de entrevistas semiestructuradas como fuente de recolección de datos y análisis de contenido para sistematizar los hallazgos. Resultados: A partir del análisis, la información se organizó en cuatro categorías temáticas: Pruebas toxicológicas y fines de su uso; Recepción y pruebas rápidas de ITS y pruebas toxicológicas; Abstinencia comprobada como criterio de derivación a la UAT; y Las consecuencias de imponer la abstinencia en el proceso de rehabilitación. Conclusión: Es necesario reflexionar sobre el proceso de atención que incluye acciones de reducción de daños, excluyendo el enfoque del tratamiento en la abstinencia.

Palavras clave: Servicios comunitarios de salud mental; Salud mental; Trastornos relacionados con el uso de sustancias; Drogadictos; Reducción de daños.

\section{Introdução}

Na construção histórica das Políticas sobre drogas no Brasil, ressaltam-se três marcos importantes para sua constitucionalização, sendo a primeira: a Lei Federal n 10.216/2001, conhecida como Lei da Reforma Psiquiátrica, que aponta o princípio do respeito aos direitos de pessoas com transtornos mentais e problemas advindos do uso de drogas, tendo assim a implementado, em 2002, os Centros de Atenção Psicossocial álcool e outras drogas (CAPS-AD), seguindo os princípios de cuidado em liberdade, a inclusão social, o atendimento integral e comunitário (Brasil, 2004).

Já o segundo refere-se à Lei no 2.197/2004, que instituiu a Política Nacional na Atenção Integral a Usuários de Álcool e outras Drogas no Sistema Único de Saúde (SUS), com enfoque na integralidade, quebrando paradigmas, visto que, políticas anteriores eram embasadas em práticas proibicionistas e na concepção antidrogas.

Nesta perspectiva, a redução de danos foi proposta como um eixo norteador, em que a centralidade da atenção em saúde na rede não se concentra necessariamente na abstinência ao uso de drogas, mas nas necessidades biopsicossociais dos indivíduos (Xavier et al., 2018).

Em relação ao terceiro marco, identifica-se a portaria 3.088/11 que criou a Rede de Atenção Psicossocial (RAPS), preconizando o tratamento e acompanhamento profissional por diversos serviços como: Unidade Básica de Saúde (UBS), Centro de Atenção Psicossocial (CAPS), Unidades de acolhimento (UAA). Diversas estratégias foram desenvolvidas nos campos técnico, assistencial, social, político e jurídico possibilitando uma nova dimensão ao conjunto das ações em saúde mental no SUS, garantia da articulação e da integração dos serviços de atenção das redes de saúde no território (Amarante \& Nunes, 2018).

Corroborando com essa trajetória histórica na transformação do cuidado ao usuário de álcool e outras drogas, cabe destacar os contextos em que a assistência, políticas públicas e o cuidado estão inseridos, ou seja, modelos de atenção e cuidado que idealizam e organizam estas redes e práticas, sendo assim uma linha tênue permanente de disputas e tensionamentos.

Nesse sentido, há os modelos: moral/criminal e modelo antimanicomial/redução de danos. O primeiro enfatiza o uso de drogas sob a perspectiva do pecado e da criminalidade, sendo a atuação pautada em ações do Estado de repressão e prisão. Considera-se o problema sob a perspectiva da doença, em que a utilização das drogas é observada como fator de risco para a dependência, em que o indivíduo não pode viver sem a droga, requerendo tratamento e reabilitação. Sendo que o único tratamento indicado é a abstinência (não uso) total das drogas, sendo os contextos de vida e as relações interpessoais desconsideradas (Teixeira et al., 2017).

Em contrapartida, o modelo antimanicomial e de redução de danos, problematizado a partir da Reforma Psiquiátrica, aborda que a abstinência é eficaz para muitas pessoas, no entanto argumenta sobre a frequente imposição desta terapêutica como requisito e/ou única via de cuidar/tratar. Nesse sentido, a abstinência elucida sua limitação para a transformação do cuidado, pois acaba reduzindo um problema social a uma questão meramente individual e biológica. Nesta perspectiva, para o sucesso na abordagem e compreensão do cuidado, é necessária uma visão ampliada sobre a utilização das drogas como parte de uma história de vida, contextos/ambientes de uso, relações e culturas (Teixeira et al., 2017). 
Considerando o exposto, este artigo traz a importância de avançar a discussão das Políticas Públicas sobre drogas, buscando analisar esse problema social, de uma forma sociocultural, que envolve aspectos de vida do sujeito, como: moradia, economia, trabalho, renda, família, modos de vida, cultura, relações, para a construção de práticas que implementem e aperfeiçoem o acolhimento e a integralidade do cuidado.

Assim, o objetivo do estudo é analisar as práticas de cuidado ao usuário de drogas em um CAPSad sobre a perspectiva da abstinência e redução de danos. Justifica-se pela necessidade de compartilhar as vivências durante o campo de pesquisa e o debate em torno do cuidado ainda focado em modelos reducionistas e biologicistas, que permeiam os serviços da RAPS, e que possa contribuir para o avanço nos contextos de práticas em saúde, na educação e formação que possibilitem ampliar horizontes para humanização no cuidado às pessoas que usam álcool e outras drogas.

\section{Metodologia}

Trata-se de um estudo com abordagem quantitativa e qualitativa realizada em seis municípios brasileiros que fazem fronteira com o Uruguai, o qual buscou acompanhar as mudanças na fronteira brasileira sob a perspectiva da nova lei de drogas do Uruguai. A primeira etapa ocorreu no ano de 2016 e a segunda, em 2017.

Os resultados apresentados neste estudo correspondem aos dados da etapa qualitativa da pesquisa, que tem abordagem qualitativa, exploratória, descritiva (Yin, 2017), obtidos em um CAPS-AD localizado na região do interior que faz fronteira entre Rio Grande do Sul (Brasil) e Uruguai. Este cenário atende brasileiros e uruguaios nacionalizados, que residem nos municípios. Participaram da coleta de dados 06 profissionais de saúde, sendo que, no enfoque deste artigo 04 trouxeram com profundidade o tema.

A escolha dos participantes, não ocorreu de modo aleatório, foram convidados trabalhadores de saúde, assistência social, que estivessem acompanhando ou assistindo pessoas em uso de substâncias psicoativas (SPA). Todos os profissionais presentes no serviço de saúde mental foram convidados a participar da pesquisa, sendo excluídos os que estavam de férias ou licença.

A coleta de dados foi realizada a partir de entrevistas semiestruturadas, que presume a utilização de um roteiro prédefinido composto por perguntas para caracterização do perfil dos sujeitos, bem como, questões norteadoras que abordavam as práticas assistenciais em saúde e os evidentes impactos da nova política de Cannabis do Uruguai na saúde brasileira (Tavares et al., 2019). Para acesso aos participantes e coleta de dados, foi empregado o método não probabilístico por conveniência, determinada pelo julgamento e interesse do pesquisador ou coletador de dados a partir do que se considera importante na população de estudo (Yin, 2017).

As entrevistas foram realizadas em uma sala reservada, agendadas previamente e gravadas por gravador MP3. Após, estas foram transcritas e analisadas através da análise de conteúdo, em três etapas: pré-análise; exploração do material; e tratamento dos resultados - interpretação (Bardin, 2015). Primeiramente, os pesquisadores realizaram uma leitura ampla dos textos transcritos de cada participante discutindo-os e após, fazia-se o aprofundamento e apontamento dos conteúdos a serem explorados na entrevista. Por fim, identificava-se pontos levantados pelos participantes e interpretava-los com apoio da literatura científica da área.

A pesquisa teve aprovação pelo Comitê de Ética e Pesquisa da Faculdade de Enfermagem (UFPel) sob o Protocolo 1.757.94/2016, sendo respeitada a Resolução 466/2012, que menciona normas às pesquisas com seres humanos. Todos participantes assinaram o Termo de Consentimento Livre e Esclarecido, sendo que, para manter o anonimato dos participantes, foram utilizados a letra P (profissional) seguido o número da entrevista: por exemplo P1 (profissional 1). 


\section{Resultados}

As categorias criadas foram: Os testes toxicológicos e as finalidades de sua utilização; Acolhimento e os testes rápidos para IST's e toxicológicos; A abstinência comprovada como critério de encaminhamento para a UAT; Consequências perante a imposição da abstinência no processo de reabilitação.

\section{Os testes toxicológicos e as finalidades de sua utilização}

Conforme descrito pelos profissionais estudados, os testes toxicológicos são realizados a partir da coleta de conteúdo biológico do aparelho urinário. Após a pessoa desprezar a urina em um frasco, mergulha-se em fitas reagentes, que detectam substâncias para a varredura de abstinência. Abaixo indica-se depoimentos sobre o tema:

Não, ele é um teste que indica tudo ali na fita [...] A gente faz a coleta no caso do material biológico: urina [...] ele vai reagir, a amostra vai reagir com o produto da fita, o reagente ali, e aí se tiver anticorpos para aquilo ali, vai acusar no teste. No caso da fita é um pouco diferente, porque ele é específico, né? É o produto, se tiver o produto na urina, aí a fita vai acusar ali também. Esse é anticorpo e aquele ali é o produto, em si. P1

Eu e a enfermeira fazemos o teste, porque no SUS ele foi dado como uma competência para o enfermeiro, né? Mas como eu sou farmacêutica bioquímica eu também acabei/porque como ela só está de manhã, então a gente dividiu os testes assim. De manhã com ela que é enfermeira e para mim de tarde. PI

A gente faz (testes) pra saber se realmente são abstinentes ou não. [...] A gente coloca na cabeça que é uma coisa que é uma rotina, que seja obrigada entendeu. [...] É uma rotina entendeu, se eles desconfiam, a gente explica que é uma rotina, aí a gente contata, infelizmente muitos. [...] Faz o confronto, não tão comum, faz uma maneira amigável se você quiser fazer faz, entendeu?! Embasamento é o teste mais para família, geralmente quando a promotoria manda, porque aí a gente fica ligadão né, se a promotoria mandou para cá. [...] a família muitas vezes é enganada. P2

\section{Acolhimento com testes rápidos para IST's e após toxicológicos}

Os profissionais pesquisados conceituam o acolhimento no CAPS-AD, a partir de alguns procedimentos padrões: além da anamnese completa relacionada ao uso abusivo de SPA e levantamento dos problemas familiares, realiza-se a coleta de material biológico para varredura de IST's e verificação dos sinais vitais. O acolhimento pode ser realizado pelos enfermeiros, farmacêuticos e psicólogos, sendo que a coleta de sangue é realizada apenas pela enfermeira e a farmacêutica.

Na realidade eu também participo do acolhimento de pacientes. Ele chega na unidade, quando ele não é paciente ainda, aí no caso, o paciente que é acolhido a gente escuta toda a história dele, faz uma entrevista com o paciente bem detalhada. Aí depois que ele passa por isso, a gente verifica os sinais do paciente, né? ele também passa pelos testes-rápidos já na primeira/nesse primeiro acolhimento. [...] É padrão, vai para uma pasta dele, tipo para ter um prontuário já inicial do paciente, mais completo. Isso foi uma medida que a gente tomou aqui em reunião há pouco tempo, há uns dois meses. P1

Foi questionado a respeito de quais procedimentos eram tomados nos casos em que houvesse resultados positivos para IST's. Nestas ocasiões, foi referido que era a praxe, encaminhar aos serviços de referência. Além disso, observa-se a realização dos testes toxicológicos: 
Como aqui é um serviço de referência aqui ele vai ser atendido na necessidade dele, de álcool e drogas. E se ele precisar de alguma outra coisa tipo, chegou um paciente aqui, fez um teste-rápido, foi verificado que ele tem hepatite ou que ele tem sífilis. Aí foi verificado o paciente, por exemplo, com sífilis, aí a gente encaminha para o serviço que referência. $P 1$

Então todo paciente que chega aqui já faz teste-rápido, né? Aí conforme o acompanhamento, esse paciente que chega aqui e depois, conforme consulta médica e o tratamento, ele vai passando pelos testes toxicológicos também. Aí conforme ele vai vindo aqui, os testes toxicológicos eu também faço. São THC, cocaína, né, todos esses, crack, que na realidade são dois testes, um que pega cocaína, crack, essas substâncias assim e outro o THC [...] Testes rápidos. P1

Sempre quando o paciente chega. Mas, no caso o toxicológico não é de primeira... Porque normalmente quando ele vem pra acolhida, ele já diz/ele já chegou aqui dizendo "Olha, preciso de ajuda, eu usei a noite inteira", né? Então esse teste ele sempre é num segundo momento pra acompanhamento. P1

\section{A abstinência comprovada como critério de encaminhamento para a UAT}

Os entrevistados referem que as vulnerabilidades socioeconômicas e rompimento de laços familiares fazem parte da realidade das pessoas cuidadas pelos CAPS-AD. Diante disso, as Unidades de Acolhimento Transitório (UAT) são dispositivos importantes para o enfrentamento de problemáticas referentes à moradia. Foi expresso que no município estudado, estava disponível esse espaço, todavia, obtinha-se critérios impostos pelos prestadores de serviços do CAPS-AD, para que a pessoa em tratamento e em situação de vulnerabilidade fosse encaminhada como a manutenção da terapêutica pautada na abstinência, confirmada por meio dos testes toxicológicos.

A UAT é assim, uma casa de acolhimento que é aqui da prefeitura municipal, mas UAT é para aquele paciente que... Ele realmente quer se tratar, ser assim de uma formala gente passa por um periodo dele aqui, ele tem que vir todos os dias aqui, a gente tem que fazer os testes neles pra ver se realmente eles não estão usando, né? P3

$E ́$, a gente faz aqueles testes de urina pra ver se ele não fumou maconha, se ele não usou crack... Se realmente em uma semana ele não usar, ele vai pra casa. Que lá eles têm um trabalho meio que terapêutico, assim, eles cuidam de hortas/mas eles são livres, entendeu? P3

\section{Consequências perante a imposição da abstinência no processo de reabilitação}

Os entrevistados refletem que ações pautadas na abstinência podem dificultar uma visão ampliada sobre o problema das drogas, promovendo uma barreira no tratamento qualificado, evidenciam-se as consequências a seguir:

E aí isso ele tem que comparecer aqui toda semana, dependendo do paciente diariamente para pegar medicação. A gente não pode liberar medicação para uma semana [...] É um problema que eu tenho aqui como farmacêutica à princípio eu não poderia mas se eu libero é perigoso, eles tomam tudo... Eles substituem o vício uma situação pela outra, entende? Então a gente tem todo um cuidado em tentar de cercar esse paciente de cuidados mesmo, para que, dependendo do psicológico dele, ele vai lá e usa todos os medicamentos que ele têm, ele toma ao mesmo tempo... P1 
E aí é que vem o principal problema, é a falta de perspectiva. Muitas vezes as pessoas voltar para a droga, tem tratamento, tem um aparato todo... Mas aí depois que sai daqui não sabe para onde caminhar, não sabe para onde ir. $P 4$

A gente gostaria que mais pacientes aderissem ao tratamento como um todo, que não é só remédio, não é só medicamento. A gente gostaria que os pacientes aderissem ao tratamento psicológico, grupo... Ai às vezes isso não acontece. $P 1$

Tem bastante abandono. [...] eu acho que tem esse perfil assistencialista que a gente vive. Não tem uma contraprestação. Aí o usuário chega aqui, muitos deles, além de bolsa família, eles também recebem benefício de prestação continuada, né? Eles ganham auxílio alimentação, porque eles almoçam no restaurante. Eles têm lanche pela manhã, lanche pela tarde. Eles então têm todo um amparo nesse aspecto e eu acho que isso não toca eles na situação de buscar perspectivas para abstinência, entende? Tu vê que as vezes o paciente vem aqui, pega medicação uma, duas semanas, é acolhido, tudo, tem tudo aquilo que te falei e depois ele some. Tipo, eu não tenho nada contra o assistencialismo em si, mas eu acho que teria que ter uma contraprestação, para tudo. P1

A dificuldade de aderir ao tratamento, mesmo, porque como são os pacientes assim, a maioria deles, assim, pessoas que não moram regradamente em casa, eles pousam uma noite em casa, duas três na rua, aí vem um dia, no outro não vem, fica muito difícil de tu fazer um tratamento nesse tipo de pessoa. P3

O que eu percebo muitas vezes que o paciente vem, por insistência da família, dos amigos, ou às vezes pela questão de trabalho. Mas que esses não dá certo o tratamento são os que abandonam... Quando a gente tem o querer do paciente, quando ele vem por busca espontânea, são os que permanecem. P4

\section{Discussão}

Revela-se como um dos principais dados da pesquisa que umas das práticas centrais nos serviços da RAPS deste município são com enfoque na abstinência.

É importante contextualizar que os modelos de tratamento são construídos historicamente com base na medicalização e abstinência a droga (modelo de doença) e criminalização (modelo moral/criminal). Este modelo proibicionista que tem características embasadas na repressão e judicialização prioriza um tratamento voltado à dependência das drogas como uma questão biológica, de dependência física, descontextualizando as realidades de vida. Discursos assim, além de reafirmar a psiquiatrização e a judicialização sobre o uso de substâncias, distorcem e limitam as possibilidades de cuidados a esses usuários (Lopes \& Gonçalves, 2018).

Apesar da prerrogativa da RAPS em garantir a autonomia da pessoa frente ao seu processo de reabilitação psicossocial, a partir da fala de P1 e P2, por exemplo, é colocada que a pessoa em sofrimento pelo uso abusivo de SPA parece não ter opção de fazer ou não a testagem toxicológica, uma das práticas para controle da abstinência a droga. Revelando-se uma prática imposta ao usuário, não está embasada por documentos legais e políticos, sendo geralmente realizada a pedido dos familiares ou promotores da justiça, tendo o intuito de saber se o usuário está ludibriando a respeito da pausa abrupta do uso de drogas.

De acordo com a Portaria 121/12 a Unidade de Acolhimento Adulto (UAA) é um ponto da atenção psicossocial, pertencente ao leque de dispositivos de cuidado a pessoas que sofrem com abuso de drogas. Funciona integralmente, sem 
pausas de horários e dias, pode ser utilizada por homens e mulheres vulneráveis socioeconomicamente ou familiar, por até seis meses. Têm entre 10 a 15 vagas e somente cidades com no mínimo 200 habitantes ou sendo referência regional podem anexar esse serviço em sua RAPS.

Na RAPS, ela tem a prerrogativa de "intensificar, ampliar e diversificar as ações orientadas para prevenção, promoção da saúde, tratamento e redução dos riscos e danos associados ao consumo de substâncias psicoativas" (Brasil, 2011). A partir de seu caráter de residência e transitório, o serviço deve dispor de uma estrutura de casa, com o intuito de proporcionar além de um lugar com o mínimo de conforto para descanso digno, interações sociais e atividades terapêuticas.

Com esta compreensão é importante enfatizar que a portaria não menciona a obrigatoriedade do seguimento da abstinência para usufruto deste. Pelo contrário, sugere diferentes possibilidades terapêuticas como foco do processo de trabalho do CAPS e UAA. Para mais, "deverá articular intersetorialmente a garantia dos direitos de moradia, educação, convivência familiar e social" (Brasil, 2012).

As pessoas acolhidas nas UAA's são encaminhadas pelo CAPS de referência e por critérios estabelecidos por este serviço, tendo tempo de permanência estipulado, ações e responsabilidades descritas no Plano Terapêutico Singular (PTS). Ressalta-se que ao utilizar apenas uma perspectiva terapêutica impossibilita-se olhar para as singularidades e necessidades de cada sujeito para desenvolver um plano de cuidado. Considerando as falas dos participantes, cabe refletir acerca de como o PTS é construído no espaço referido: quando se oferta apenas abstinência como forma de cuidado e se introduz testes toxicológicos de confrontação do discurso do sujeito, o PTS é desenvolvido embasado em que e quais necessidades?

As falas dos profissionais da pesquisa apontam a utilização de métodos de abstinência e controle, como as coletas de material biológico para exames nos quais, algumas vezes, nem é acordado com o usuário. Observa-se que faz parte da rotina, no primeiro momento são realizadas as testagens para IST's, protocolado no serviço enquanto prática que deve ser realizada em todas as pessoas acolhidas. Após o acolhimento e tendo iniciado o tratamento para o uso abusivo de SPA, a pessoa passa a seguir outra perspectiva terapêutica, em que é acompanhada por intermédio dos testes toxicológicos. Conforme a entrevista da profissional farmacêutica que relata que esses testes são para detectar THC (componente da maconha), cocaína, crack: um para cocaína e crack e outro para verificar se a pessoa consumiu maconha.

Outra questão apontada nos dados da pesquisa são os protocolos necessários para realização do atendimento ao usuário. Referem que além de manterem-se abstinentes, para poderem utilizar a UAT era necessário frequentar o CAPS-AD todos os dias. Se em uma semana a pessoa comprovou a não utilização de substâncias psicoativas, estava apta a usufruir do serviço. Os testes para confirmação da abstinência eram realizados por conteúdo urinário.

Subentende-se que algumas pessoas se encaixam nas possibilidades, outras não. Como se estabelece que somente indivíduos abstinentes possam ser encaminhados as UAA's, além de excluir as outras formas de cuidado, pode impossibilitar que pessoas que precisam deste espaço, possam usufruí-lo.

Enquanto a abstinência for vista como salvação e saúde, as contínuas recaídas que acontecem durante o tratamento serão vistas como doença, impedindo que a pessoa que faz uso de substancia tenha sua demanda de cuidados acolhida, dificultada seu acesso ao serviço, indo a uma lógica focada na droga, que julga e não compreende as diferenças do usuário (Carvalho \& Dimenstein, 2017).

Este modelo hegemônico de doença não é efetivo e resolutivo, faz referência ao poder psiquiátrico, relacionando ao domínio, à tentativa de subjugar e fortalecer modelos asilares bem como a criação e manutenção dos loucos, neste caso "os drogados". Além de colidirem com os princípios do SUS e RAPS, por não priorizarem o tratamento, indo de encontro a um imaginário social segundo o qual algumas pessoas como - os pobres, usuários de drogas - são vistas como pessoas que descumprem determinadas normas sociais e que, portanto, deve-se garantir o controle sobre o tratamento, com utilização do medicamento e da disciplina (Lopes \& Gonçalves, 2018). 
No caso desta pesquisa, fala-se dos testes de abstinência e controle de IST's que refletem a cura do doente, o controle e biologização da vida.

A dificuldade do trabalho com usuários de drogas de forma compreensiva e integral é apontada em estudos, que identificam a carência de serviços que levem em conta as necessidades e características dos usuários de drogas e que compreendam o fenômeno enquanto sociocultural (Xavier et al., 2018; Silva et al., 2020a). Sendo que um estudo com usuários de drogas que também estão em situação de vulnerabilidade, há a denúncia do descaso e as fragilidades das políticas públicas e do Estado em abordar o tema, pois há uma descontextualização das necessidades dos sujeitos e uma simplificação de suas histórias de vida. Por serem usuários de drogas que se encontram em situação de rua já os coloca em desvantagem no sistema: para eles resta o abandono, a exclusão, a morte ou um "grito" para acesso à saúde. As políticas públicas que deveriam ajudar, os estigmatizam, aumentando seu sofrimento e desnudando a exclusão social (Silva et al., 2020a).

Deste modo, os profissionais de saúde apresentam suas limitações e despreparo para lidar com o tema das drogas, talvez pelas fragilidades na formação em saúde, bem como, pelas interfaces com o Estado e a mídia, que ainda negligenciam o tema, tratando como problema individual e comportamental dos sujeitos envolvidos. Isso pode ser exemplificado, pelo caso da higienização social das Cracolândias em São Paulo (2016), em que pessoas em situação de rua usuárias de drogas foram removidas de seus territórios sociais, com o argumento de estarem sujando o espaço, utilizando drogas, envolvendo-se com crimes, e deturpando a segurança da sociedade. No entanto, não foi pensado um lugar de acolhimento para estas pessoas, e suas histórias de vida de sofrimento e abandono (Silva et al., 2020b).

Em nossa pesquisa, fica evidenciado nos depoimentos dos profissionais que a imposição vertical de cuidado, o não protagonismo do usuário, obrigatoriedade da realização dos testes toxicológicos, para controlar as ações de consumo de SPA ilegais, obtinham consequências importantes no cotidiano do processo de trabalho dos serviços, o principal exemplo seria a falta de projetos de vida e medicalização excessiva. A fala de P1 revela que dispensava medicamentos diariamente ou semanalmente, a depender do usuário. A justificativa estava atrelada ao risco do usuário consumir doses elevadas dos fármacos, já que, para manterem-se abstinentes, supriam ou substituíam a substância de abuso (provavelmente ilegal) por aquelas dispensadas pelo serviço.

Neste sentido, observa-se que não há a criação de um processo terapêutico, que tire o foco da droga, realizando então somente uma troca da droga pela medicalização. O vazio das relações e de propostas de acolhimento e projetos de vida dá lugar a práticas com resultados rápidos em vistas ao controle: $\mathrm{O}$ importante é não usar a droga.

Como visto este CAPS-AD não trabalha com outras perspectivas terapêuticas, alternadas a abstinência. Observou-se por P1 que se tem conhecimento da linha de cuidado pautada na Redução de Danos (RD), mas que não era ofertada. Neste sentido, o profissional revela que, apesar do suporte desempenhado pelo serviço, os usuários (grande parte) tornam a usar SPA.

Os avanços nas políticas públicas sobre drogas no Brasil desde 2002, na mudança de nomenclatura de Política Antidrogas para Política sobre Drogas, e com as primeiras discussões sobre RDs e políticas de cuidado intersetoriais ainda permanecem centrados na criminalização das drogas e em terapias tradicionais. No entanto, a RD se apresenta como o início do debate de políticas e ações mais sensíveis a realidade do usuário de SPS, visto que, propõem a necessidade de escuta da experiência de vida e adaptações de ações para redução de riscos, como por exemplo, trocar uma droga de maior risco por outra menos agressiva biologicamente, evitar situações de risco com o uso de preservativos, por exemplo, e conversar sobre a utilização de drogas e violência (Silva et al., 2018).

É necessário pensar no debate sobre a redução de danos, que reflete uma forma de acolhimento. O acolhimento se trata principalmente da chegada do usuário ao serviço, sendo um dos momentos cruciais para o profissional também, pois é quando se podem planejar os passos da terapêutica, alinhavar os cuidados e ofertar o leque de possibilidades para a pessoa 
(oficinas, grupos, atividades, etc). Uma recepção pautada no estigma, preconceito e moralizadora é passível de que todo o processo tenha resultados negativos ou pior, da pessoa abandonar a terapêutica, antes mesmo de começar.

O conceito de acolhimento revela que "quando o profissional causa no usuário algo bom ou 'nem tão bom assim', ele está agindo, afetando o corpo, a vida do outro, o usuário. Os sentimentos despertados em mim, o profissional ocasionado pelo encontro com o outro, são da ordem das paixões. Ação e paixão nessa troca de olhares, escapando da unilateralidade. No decorrer dos encontros e da construção e da reconstrução do PTS, que também é um projeto de vida, sendo que, quanto mais afetos positivos forem sentidos, maior a potência de agir, melhor a relação terapêutica, maior a motivação, mais produção de saúde" (Romanini, Guareschi \& Roso, 2018). Neste sentido, quando já na recepção, a pessoa tende a impor cuidados e não construir em conjunto há a tendência de não haver a possibilidade de vínculo e escuta entre os envolvidos.

Neste contexto, a RD faz parte destes processos de acolhimento, vínculo, escuta e criação de projetos terapêuticos, se constituindo em uma perspectiva ampliada para a visão do fenômeno das drogas, porém apontada em nossa pesquisa enquanto um desafio pouco problematizado pelos serviços de saúde. Isso é também refletido em outros estudos que mostram que os profissionais de saúde encontram dificuldades em cuidar pessoas sob a lógica da RD por desconhecerem as políticas de saúde mental no contexto biopsicossocial, sendo essa possível, e as pré-concepções e estigmatização dos trabalhadores em relação ao usuário de drogas. Estas barreiras podem ser um dos obstáculos para o não desenvolvimento técnico de habilidades em saúde, tendo como consequência, a ineficácia da rede de serviços para auxiliar na resolução de problemas advindos do uso abusivo de drogas (Vargas \& Campos, 2017; Lima, Oliveira \& Lima, 2019).

Pesquisa realizada com trabalhadores do NASF revelou que enquanto $36,4 \%$ dos participantes conheciam o cuidado sob a lógica de Redução de Danos, 26,32\% - não a conheciam, ou melhor, demonstraram total desconhecimento em relação a essa linha de cuidado. Tratando-se da convivência com pessoas que consomem SPA, 55,5\% referiram que considera difícil e 22,2\% mencionaram que não conviveriam com usuários de cocaína e crack, bem como, não recomendariam essa linha de cuidado. $68,4 \%$ dos entrevistados mencionaram que o uso de quaisquer drogas - tem potencial para ocasionar dependência química, sendo que, 47,4\% relacionou esse problema à substância propriamente dita, e 52,6\% a pessoa que está enfrentando o problema. Quando se tratou das medidas alternativas de cuidado, $42,1 \%$ dos profissionais referiram enquanto eficaz a repressão policial e/ou 36,8\% por profissionais de saúde (Vargas \& Campos, 2017).

Esses dados parecem ir de encontro aos resultados apresentados neste artigo, uma vez que, propõem refletir a respeito da imposição da terapêutica pautada nos valores morais dos trabalhadores, que desconsidera a singularidade humana, possibilidades terapêuticas alcançáveis pelo indivíduo em sofrimento, podendo inclusive dificultar o acesso e a adesão ao cuidado em saúde mental.

Segundo P1 e P3 há o reconhecimento de que somente a abstinência não resolve os problemas de uso de drogas, visto que, observam que os usuários se apegam ao uso da medicação, dando continuidade a um suposto "vício". Apesar de entenderem que uma proposta de cuidado adequada levaria em consideração a realização de atividades de lazer, grupais, de psicoterapia, o que poderiam ajudá-los a entender seus contextos, ainda não conseguem enquanto trabalhadoras saírem de uma proposta reducionista.

Com a ausência de convivência com o usuário no tratamento, não é possível desenvolver o sentimento de empatia entre os agentes permeados no cuidado, havendo o impedimento da contextualização do lugar que a substância ocupa na vida do indivíduo e os gatilhos que desencadeiam o seu uso. Outro fato que é apontado por P4 é a necessidade de haver o desejo do usuário pelo tratamento, não somente da família, trabalho, profissionais.

Como resultado desse processo tem-se, em muitos casos, a evasão nos serviços de saúde e a inconclusão terapêutica, restando ao usuário essa responsabilidade de não adesão ao cuidado. Isso é evidenciado nas falas: "tem muito assistencialismo", "eles moram na rua, não tem regras", faz jus a reflexões sobre a visão biomédica do uso de drogas, que o 
reduz ao um foco somente biológico, desconhecendo as questões socioculturais que fazem parte deste processo: os contextos, os determinantes sociais, as questões de estigma e preconceito. Como resultado, o profissional não reflete suas relações com o problema, culpabilizando somente a pessoa que utiliza a droga.

Entende-se que as raízes da compreensão sobre o uso de drogas na sociedade, historicamente estão colocadas com bases no conceito de "comportamento de risco" que se restringe a uma abordagem individual, ou seja, de responsabilização exclusiva do indivíduo por seus comportamentos e atitudes para aquisição da doença, criando uma postura de "culpabilização" e "punição". Isso foi evidenciado na década de 80 no uso de drogas injetáveis, o HIV e a AIDS, que reforçam a ideia de estigmatização e preconceito, desconsiderando a necessidade de práticas de cuidado envolver a percepção de múltiplos fatores, sendo eles: políticos, sociais, culturais (Ayres, Castellanos \& Baptista, 2018).

A ideia de comportamento de risco na área de drogas reforça as concepções biomédicas de cuidado na área de atenção em saúde, onde não há diálogo entre profissional e usuário e tem por base analítica os sinais e sintomas, e as condutas para curar o corpo desprovido de história. As ferramentas de ensino e o processo da ciência e do conhecimento nasceram do estudo exato do corpo e de suas funções a partir da abertura do cadáver, ou seja, o relacionamento profissional-paciente é fundado sobre o corpo morto, desprovido de história, necessidades e subjetividades (Santos, 2019; Paiva, Ayres \& Buchalla, 2012).

Estas concepções são observadas em nossa pesquisa, em que ainda se nota profissionais formados somente por base do modelo biomédico, que não refletem e também julgam as histórias de vida que são diferentes das suas.

Para tal, é necessário investir em um movimento de reflexão e problematização sobre a formação em saúde na Universidade e de forma permanente nos serviços da rede, buscando conhecer e ocupar espaços sociais que percebam a saúde forma ampliada (debates dentro e fora dos serviços), considerando aspectos socioculturais como a família, os contextos de vida, questões políticas, econômicas, culturais, redes de afeto. Sendo que, a proposta de redução de danos vai ao encontro do acolhimento, observação e trabalho a partir das diversas vivências e histórias de vida, sendo essencial na incorporação na formação de saúde.

\section{Considerações Finais}

No presente estudo que analisou as práticas de cuidado ao usuário de drogas em um CAPS ad sobre a perspectiva da abstinência e redução de danos foi possível evidenciar que uma das práticas centrais nos serviços que compõem a RAPS deste município, o enfoque dado ao tratamento está restrita à abstinência.

A obrigatoriedade da realização dos testes toxicológicos, como procedimento padrão realizado em todas as pessoas acolhidas foi identificada nas falas dos profissionais para detectar o consumo de SPA ilegais e também como critério de encaminhamento para continuidade de cuidado, manutenção e controle de uso nos serviços CAPS AD e UAA.

Apesar das diretrizes que fundamentam a RAPS referirem garantir a autonomia do sujeito frente ao seu processo de reabilitação psicossocial, os dados da pesquisa revelaram que os sujeitos que fazem uso de SPA não possuem outras opções de recursos terapêuticos que não sejam a testagem toxicológica como prática de detecção e controle da abstinência a droga.

$\mathrm{O}$ tratamento pautado na abstinência dificulta uma visão ampliada sobre o problema das drogas, além de promover uma barreira no tratamento impossibilitando olhar para as singularidades e as necessidades de cada sujeito dificultando assim desenvolver um plano de cuidado com enfoque mais realista das consequências de uso e alternativas de estratégias de redução de danos.

Há uma preocupação perante a imposição da abstinência no processo de reabilitação, pois observa-se que em muitos casos há abandono do tratamento e recaídas. Essa postura proibicionista contribui com a estigmatização e desestimula o acesso aos serviços de saúde e outras áreas. 
Ressalta-se que os dados desta pesquisa contribuem para a assistência e o ensino na saúde no cenário sociocultural, pois fornece visibilidade sobre o debate acerca da redução de danos enquanto um desafio pouco problematizado pelos serviços de saúde. A RD além de um recurso terapêutico que visa prevenir as consequências negativas do consumo da droga, flexibiliza a exigência automática e imediata da abstinência. Reforça uma proposta política democrática que tem em seu propósito a compreensão sobre o uso da droga, a partir dos saberes e as experiências dos próprios sujeitos.

Cabe apontar como limitações deste estudo a realização da coleta de dados ter sido realizada por um número reduzido de participantes, apenas um grupo de interesse, os profissionais da saúde, assim como a utilização de um único cenário. Entende-se que a inclusão de diferentes grupos de interesse, em especial a participação do usuário de drogas e familiares propicia discussões mais aprofundadas e conhecimentos sobre o tema.

Por fim, indica-se a importância do investimento em pesquisas qualitativas para compreensão do universo do cuidado aos usuários de drogas, buscando aprofundar elementos da vivência no cotidiano dos serviços de saúde, seus desafios, os modelos de cuidado, as garantias de direitos, a acessibilidade e equidade, visto que, essa imersão possibilita a reflexão e ampliação para novos olhares sobre as políticas públicas em drogas no Brasil.

\section{Agradecimentos}

Agrademos ao Instituto de Pesquisa Econômica Aplicada (IPEA), pelos recursos financeiros investidos nesta investigação social, política e científica.

\section{Referências}

Amarante, P., \& Nunes M. O. (2018). A reforma psiquiátrica no SUS e a luta por uma sociedade sem manicômios. Ciênc. Saúde Colet, 23(6), 2067-74.

Ayres, J.R., Castellanos, M. E. P., \& Baptista, T. V. F. (2018). Entrevista com José Ricardo Ayres. Saúde e Sociedade, 27(1), 51-60.

Bardin, L. (2015). Análise de conteúdo. (7a ed). Edições.

Brasil (2004). Saúde mental no SUS: os centros de atenção psicossocial. Secretaria de Atenção à Saúde. Departamento de Ações Programáticas Estratégicas. Brasília.

Brasil (2011). Portaria n 3.088 , de 23 de dezembro de 2011. Institui a Rede de Atenção Psicossocial para pessoas com sofrimento ou transtorno mental e com necessidades decorrentes do uso de crack, álcool e outras drogas, no âmbito do Sistema Único de Saúde (SUS). Diário Oficial da União - 24/12/2011.

Brasil (2012). Portaria $\mathrm{n}^{\mathrm{o}}$ 121, de 25 de Janeiro de 2012. Institui a Unidade de Acolhimento para pessoas com necessidades decorrentes do uso de Crack, Álcool e Outras Drogas (Unidade de Acolhimento), no componente de atenção residencial de caráter transitório da Rede de Atenção Psicossocial. Diário Oficial da União - 26/07/2012.

Carvalho, B., \& Dimenstein, M. (2017). Análise do discurso sobre redução de danos num CAPSad III e em uma comunidade terapêutica. Temas Psicol, 25(2):647-60.

Lima, A. F., Oliveira, P. R. S., \& Lima, S. C. F. (2019). Saúde mental e redução de danos na atenção primária: concepções e ações. Psicologia em Estudo, Maringá, 24 e40502:1-14.

Lopes, H. P., \& Gonçalves, A. M. (2018). A política nacional de redução de danos: do paradigma da abstinência às ações de liberdade. Pesquisas e Práticas Psicossociais, 13(1), e1355, 1-15.

Romanini, M., Guareschi, P.A., \& Roso, A. (2017). O conceito de acolhimento em ato: reflexões a partir dos encontros com usuários e profissionais da rede. Saúde Debate, 41(113): 486-99.

Silva, A. B., Olschowsky, A., Nunes, C. K., Braga, F. S., \& Botega, M. S. X. (2020a). Homeless persons and villages: drugs, social marginalization, and territory of care. Revista Brasileira de Enfermagem, 73(1):1-8.

Silva, A. B., Olschowsky, A., Wetzel, C., Silva, T. J., \& Pavani, F. M. (2020b). Desvelando a cultura, o estigma e a droga enquanto estilo de vida na vivência de pessoas em situação de rua. Ciênc. saúde coletiva, 25(10):3713-21.

Silva, A. B., Olschowsky, A., Wetzel, C., Silva, T. J., Rozado-Pedron, A., \& Pavani, F. M. (2018). As territorialidades de cuidado: reflexões interdisciplinares acerca do uso de drogas e o cuidado sociocultural. REME. Rev Min Enferm, e-1150, 1-5.

Vargas, A. F. M., \& Campos, M. M. (2020). Impasses na conformação da rede de atenção psicossocial pela perspectiva dos agentes institucionais. Psicologia \& Sociedade, 32, e187347, 1-18. 
Research, Society and Development, v. 10, n. 6, e41010615897, 2021

(CC BY 4.0) | ISSN 2525-3409 | DOI: http://dx.doi.org/10.33448/rsd-v10i6.15897

Santos, B. M. (2019). O corpo nos contextos de cuidado: reflexões sobre as concepções no campo de enfermagem. Aceno, 6(12), $233-246$.

Paiva, V., Ayres, J. R., \& Buchalla, C. M. (2012). Vulnerabilidade e direitos humanos: prevenção e promoção da saúde: da doença à cidadania. (1ª ed.). Curitiba: Juruá.

Tavares, D. H., Franchini, B., Biondi, H. S., Jardim, V. M. R., Rodrigues, C. G. S. S., \& Camargo, P. O. (2019). Rituais de consumo de "cannabis. Revista de Enfermagem da UFSM, 9, 1-11.

Teixeira, M. B., Ramoa, M. L., Engstrom, E., \& Ribeiro, J. M. (2017). Tensões paradigmáticas nas políticas públicas sobre drogas: análise da legislação brasileira no período de 2000 a 2016. Ciênc. saúde coletiva, 22(5), 1455-66.

Xavier, R. T., Limberger, J., Monteiro, J. K., \& Andretta, I. (2018). Políticas públicas de atenção aos usuários de drogas no contexto brasileiro: revisão narrativa de literatura. Pesquisas e Práticas Psicossociais, 13(1), e1339, 1-12.

Yin, R. K. (2016). Pesquisa qualitativa do início ao fim. Série Métodos de Pesquisa. Penso. 